\title{
A TEORIA DA MATÉRIA E AS HIPÓTESES COSMOLÓGICAS DE DESCARTES
}

\author{
Claudemir Roque Tossato ${ }^{1}$ \\ Paulo Tadeu da Silva ${ }^{2}$
}

RESUMO: Este artigo visa analisar alguns aspectos da cosmologia cartesiana, tendo em vista a teoria dos vórtices elaborada por Descartes e sua relação com a sua teoria da matéria. Nesse contexto, pretendemos mostrar como a explicação cartesiana sobre os movimentos planetários procurou oferecer uma resposta aos problemas cosmológicos que se apresentaram entre o final do século XVI e a primeira metade do século XVII, os quais determinaram o abandono do modelo cosmológico aristotélicoptolomaico e, com isso, a necessidade de uma nova concepção sobre o mundo celeste.

PALAVRAS-CHAVE: Descartes; Cosmologia; Vórtices; Mecanicismo; Matéria; Movimento; Copernicanismo.

ABSTRACT: This article aims to analyze some aspects of Cartesian
cosmology, in view of the vortex theory elaborated by Descartes
and his relationship with his theory of matter. In this context,
we intend to show how the Cartesian explanation of planetary
motions sought to provide an answer to the cosmological problems 
that appeared between the late sixteenth century and the first half of the seventeenth century, which led to the abandonment to the Aristotelian-Ptolemaic cosmological model and with this, the need for a new conception of the heavenly world.

KEYWORDS: Descartes; Cosmology; Vortices; Mechanism; Matter; Movement; Copernicanism. 


\section{A GÊNESE DA COSMOLOGIA CARTESIANA E OS PROBLEMAS COSMOLÓGICOS}

A publicação da Revolução dos orbes celestes (1996 [1543]), de Copérnico, marca o início de um longo e intenso período de debate em torno da natureza dos movimentos dos corpos celestes e, nesse contexto, da rejeição ou defesa da mobilidade da Terra, bem como do seu lugar no sistema solar. Até a publicação dessa obra, o modelo aristotélico-ptolomaico não possuía um modelo rival, um sistema que explicasse o funcionamento da máquina celeste com hipóteses diferentes daquelas oferecidas por Aristóteles e Ptolomeu. Em 1644, Descartes publica uma de suas últimas obras, os Princípios de filosofia (2006 [1644]), texto no qual ele retoma uma série de hipóteses e explicações sobre o mundo natural, terrestre e celeste. Como dissemos, trata-se de uma retomada, pois, de fato, essas hipóteses e explicações foram primeiramente apresentadas em outras obras, uma das quais não veio a público em virtude do desfecho da defesa galileana do copernicanismo. A primeira delas, O mundo (2009 [1633]), escrita entre o final de 1629 e o fim de 1633, está claramente vinculada ao copernicanismo e, por este motivo, bem como em virtude da condenação de Galileu, Descartes abre mão da sua publicação, decisão que ele comunica a Mersenne em uma série de cartas entre novembro de 1633 e maio de 1634 (cf. AT, I, p. 270-3, 280-4, 284-91). A segunda obra foi publicada em 1637, juntamente com o Discurso do método (2009 [1637]), como um dos ensaios que o acompanham. Trata-se de Os meteoros.

Não há seguramente uma correspondência entre $O$ mundo e Os meteoros (2009 [1637]), tal como aquela existente entre o primeiro e os Princípios de filosofia. De fato, as duas primeiras obras não têm o mesmo caráter. Enquanto $O$ mundo contém 
uma exposição voltada para a apresentação da teoria da matéria, da cosmologia e da natureza da luz, Os meteoros são dedicados ao exame e explicação dos fenômenos meteorológicos, ou seja, aqueles que são observados sobre a terra e no céu próximo (cf. DE BUZON, 2009, p. 17). Contudo, não obstante a diversidade de seus objetos, o primeiro discurso de Os meteoros, dedicado à natureza das coisas terrestres, contém a exposição da teoria da matéria cartesiana, assunto também abordado pelo autor nos capítulos 2, 3, 4 e 5 de $O$ mundo.

Mas o interesse com respeito aos Meteoros não repousa apenas neste fato. $\mathrm{Na}$ verdade, ao considerarmos os dois textos, podemos perceber que a mesma concepção de matéria permite a Descartes tratar os fenômenos terrestres e celestes de modo análogo. Portanto, é por meio de um mesmo conjunto de suposições sobre a natureza da matéria que Descartes explica, de um lado, os vapores, as exalações, o sal, os ventos, as nuvens, a neve, a chuva, o granizo, as tempestades, o relâmpago, o arco-íris, os círculos ou coroas que se vê eventualmente em torno dos astros e os paraélios, e, de outro, a rotação e translação dos planetas, bem como a trajetória dos cometas. São justamente esses últimos fenômenos celestes que serão retomados por Descartes na obra de 1644. Como afirma Garber, ainda que a correspondência entre $O$ mundo e os Princípios de filosofia não seja absolutamente exata, a segunda parte dos Princípios de filosofia corresponde aos capítulos 6 e 7 de $O$ Mundo, ao passo que as partes III e IV correspondem aos capítulos de 8 a 15 (cf. GARBER, 1992, p. 26). São justamente nesses capítulos da obra de 1633 que encontramos a primeira formulação da cosmologia de Descartes, introduzida por meio de uma estratégia (DESCARTES, 2009 [1633], p. 71): "Permiti a vosso pensamento, pois, por um pouco de tempo, que saia deste 
mundo para conseguir ver um outro totalmente novo, que farei nascer em sua presença nos espaços imaginários.” A estratégia consiste em tomar esse "novo mundo" como imaginário, mas cujas leis naturais podem ser observadas no "antigo mundo". De fato, ao enunciar a primeira regra deste novo mundo, a saber, "que cada parte da matéria em particular permanece sempre no mesmo estado enquanto o encontro com outras não a obrigue a alterá-lo" (DESCARTES, 2009 [1633], p. 85), Descartes afirma que "Não há ninguém que não creia que essa mesma regra se observa no antigo mundo, no tocante ao tamanho, à figura, ao repouso e mil outras coisas semelhantes (...)"(DESCARTES, 2009 [1633], p. 85). Essa estratégia remete ao modo como Bellarmino compreendia que se poderia afirmar o movimento da Terra e a centralidade do Sol, tal como expresso na carta a Foscarini, datada de 12 de abril de 1615 (cf. GALILEI, 2009, p.131-6; cf. EN, 12, p. 171-2). O compromisso instrumentalista de Bellarmino, segundo o qual as hipóteses astronômicas não são explicativas e, portanto, nem verdadeiras nem falsas, mas apenas descrevem e representam o que se observa nos céus visando salvar as aparências (MARICONDA \& VASCONCELOS, 2006, p. 98-9), permitia o tratamento das hipóteses copernicanas ex suppositione. E, em certo sentido, é exatamente esse o caminho tomado por Descartes ao explicar os movimentos celestes por meio da construção desse novo mundo imaginário. Em certo sentido, pois, levando em consideração a carta endereçada a Mersenne no final de novembro de 1633, seu posicionamento não foi o de um instrumentalista convicto e sincero (AT, I, p.270-1, apud GAUKROGER, 1999, p. 358-9):

Eu havia tencionado enviar-vos Le Monde como presente de Ano Novo [...] mas, nesse meio tempo, procurei 
descobrir, em Leiden e Amsterdã, se seria possível obter um exemplar do Sistema do mundo de Galileu, pois julguei ter ouvido dizer que ele fora publicado na Itália no ano passado. Disseram-me que o livro foi realmente publicado, mas que todos os exemplares foram queimados em Roma e que Galileu foi preso e condenado a pagar uma multa. Fiquei tão surpreso com isso que quase resolvi queimar todos os meus trabalhos, ou, pelo menos, não permitir que ninguém os visse. Era-me impossível imaginar que ele - um italiano e, segundo creio, um homem que está nas boas graças do papa - pudesse ser transformado em um criminoso, apenas por haver tentado, como certamente fez, provar que a Terra se move [...] Devo admitir que, se essa visão for falsa, falsos serão também todos os fundamentos de minha filosofia, pois é possível demonstrá-la com muita clareza a partir deles. E ela é a tal ponto parte integrante de meu tratado, que eu não poderia retirá-la sem tornar defeituoso o trabalho inteiro. A despeito de tudo isso, porém, eu não gostaria de publicar um discurso com uma só palavra que a Igreja desaprovasse, de modo que prefiro suprimi-lo a publicá-lo de forma mutilada.

Tal declaração mostra claramente o envolvimento de Descartes com o copernicanismo, contudo, a maneira como tratou suas hipóteses e explicações cosmológicas em $O$ mundo está revestida de uma retórica que visa adequar suas convicções ao modo instrumentalista de encarar os problemas astronômicos e cosmológicos. Com a condenação de Galileu, e a consequente desistência de publicar $O$ mundo, Descartes passa a dedicar-se a outros objetos de investigação, os quais, como dissemos, serão abordados nos ensaios que acompanham o Discurso do método. Ele só retornará aos assuntos cosmológicos na obra de 1644, os Princípios de filosofia. E nesse momento é importante notar 
a adoção de uma nova estratégia que, novamente, enfraquece o caráter realista de suas hipóteses cosmológicas. Como podemos observar em alguns momentos da terceira parte dos Princípios de filosofia, Descartes adverte que suas hipóteses podem ser falsas.

A adoção do sistema copernicano envolveu uma dificuldade fundamental, vinculada às dificuldades de ordem empírica. (MARICONDA \& VASCONCELOS, 2006, p. 53-4)

O principal problema enfrentado pelo sistema heliocêntrico de Copérnico está, sem dúvida, na falta de evidência empírica em favor de suas hipóteses. De fato, não há quem possa, com base na experiência comum, hoje e no século XVII, afirmar que se dá conta dos movimentos terrestres. Quem pode, por exemplo, dizer que percebe que a Terra gira em torno de si mesma? O fato de o Sol e os demais astros nascerem todo dia a leste e porem-se a oeste não prova que a Terra gira; ao contrário, fortalece o ponto de vista geocêntrico de que a Terra está parada no centro, em torno do qual vemos todos os corpos celestes moveremse em movimento circular. Enfim, nenhuma experiência simples evidencia o movimento de nossa morada; ao contrário, nossa percepção cinética interna gera, até mesmo, a certeza da imobilidade do chão que pisamos.

Tal dificuldade, contudo, deve ser contrabalançada com as novas observações astronômicas ocorridas a partir do final do século XVI, as quais desencadearam o debate em torno dos sistemas ptolomaico, copernicano ethychoniano. Chamamos a atenção aqui para algumas delas. As primeiras são dois trabalhos de observações sistemáticas de Thycho Brahe: a nova de 1572 e o cometa de 1577. As segundas são as observações feitas por Galileu com o auxílio do telescópio, dentre as quais as observações do relevo lunar, dos 
satélites de Júpiter e das fases de Vênus, merecem destaque. Ora, as observações feitas por Brahe colocavam em evidência uma dificuldade cosmológica fundamental. O problema cosmológico básico provém da seguinte questão posta por Tycho Brahe para os astrônomos: o que faz que um planeta se mova? Tal pergunta ocorre principalmente pela dissolução do cosmo aristotélico. Essa dissolução trouxe uma grande dificuldade para os cosmólogos do final do século XVI e início do XVII. Lembremos que esse período da história da astronomia é marcado fundamentalmente pela disputa entre os adeptos dos modelos ptolomaicos, para os quais a Terra é o centro de movimentos dos corpos celestes, e as novas propostas cosmológicas de Copérnico, que admite o Sol como centro de movimentos e a Terra movimentando-se ao seu redor. Brahe nunca foi copernicano, longe disso; seu universo híbrido, no qual a Terra está no centro, com a Lua e o Sol girando ao seu redor, enquanto os planetas giram, por sua vez, em torno do Sol, procura dar conta das dificuldades apresentadas por fenômenos astronômicos observados por Brahe.

Os fenômenos de 1572 e 1577 demonstraram a Brahe que o céu é corruptível, porque a existência das esferas de cristal da cosmologia aristotélica é incompatível com a trajetória dos cometas, dado o fato de que um cometa não é um fenômeno atmosférico, mas que corta o céu constantemente (cf. TOSSATO, 2004). Mas, se não existem esferas de cristal e o céu é "vazio", temos a seguinte questão: o que move os planetas? Brahe era um anticopernicano e resolveu esse problema com o seu sistema híbrido. Para um copernicano, como Kepler, Galileu e Descartes, a questão é mais sensível, pois a Terra é um planeta. Assim, o legado de Brahe foi colocar um grande problema para os cosmólogos do século Xvir. Como não existem esferas de cristal, as quais eram responsáveis pelo movimento dos planetas, o que os leva a 
se moverem? E, mais do que isso, Brahe não mostra apenas que não é possível existir esferas de cristal no céu, mas qualquer coisa que impossibilite a ocorrência de fenômenos celestes, pois esses cortariam os planos das órbitas dos planetas no céu, como, por exemplo, faria um cometa.

As observações astronômicas de Galileu, por sua vez, fortalecem os argumentos contra a distinção entre mundo sublunar e supralunar, bem como ampliam as razões que fortalecem a plausibilidade do sistema copernicano. No primeiro caso, a observação do relevo lunar permite inferir a homogeneidade entre a superfície terrestre e a superfície lunar. Portanto, conduz à recusa de duas regiões distintas, tal como a tradição aristotélica defendia. A observação das fases de Vênus, por sua vez, permite responder a um dos argumentos contra a centralidade do Sol e o movimento dos orbes celestes em torno dele. De fato, um dos efeitos que deveria ser observado, caso Vênus orbitasse em torno do Sol, seria a presença de fases. Até o advento do telescópio tal efeito não fora observado e o uso deste instrumento permitiu justamente tal observação. A descoberta dos satélites de Júpiter e os seus movimentos em torno deste planeta contribuem, mais uma vez, para o fortalecimento da plausibilidade do sistema copernicano. E isso por um motivo fundamental: o princípio de harmonia sistêmica. De fato, a observação dos satélites de Júpiter e seu comportamento responde uma objeção importante contra o movimento terrestre e, além disso, é também determinante para a deflagração da militância pró-copernicana de Galileu. Como afirma Leitão (LEITÃO, 2010, p. 82):

Os historiadores concordam em geral que a descoberta dos satélites de Júpiter, esvaziando assim a objeção que pretendia negar o movimento da Terra pela impossibilidade 
de a Lua a acompanhar, foi um fato decisivo na conversão de Galileu a um copernicanismo explícito e militante.

Feitas essas considerações iniciais, passemos ao exame das suposições cartesianas sobre a natureza da matéria e, em seguida, para a análise da teoria dos vórtices.

\section{AS HIPÓTESES CARTESIANAS SOBRE A NATUREZA DA MATÉRIA}

Tendo em vista os principais objetivos deste artigo, limitaremos a exposição sobre a teoria cartesiana da matéria aos elementos presentes na segunda parte dos Princípios de filosofia. Ainda assim, cabe lembrar novamente, ainda que de modo muito breve, que a concepção cartesiana sobre a natureza da matéria tem a sua primeira formulação em $O$ mundo e, posteriormente, em dois dos ensaios que acompanham o Discurso do método, a saber: A dióptrica e Os meteoros. Dentre esses dois últimos textos, o segundo tem certamente maior importância, uma vez que a teoria da matéria desempenha um papel fundamental em todo o restante do texto, no qual Descartes procura explicar uma série de fenômenos meteorológicos. Em A dióptrica a importância da teoria da matéria está estreitamente relacionada com a explicação sobre a natureza da luz, discutida principalmente no primeiro discurso. Feitas essas brevíssimas observações, passemos aos Princípios de filosofia.

Ao iniciar sua exposição sobre a natureza e as propriedades das coisas materiais Descartes afirma (DESCARTES, 2006 [1644], p. 59-60): 
Ora, porque Deus não nos engana, dado que isso repugna à Sua Natureza, como já antes observamos, devemos concluir que existe uma certa substância extensa em comprimento, largura e altura que está presente no mundo [com todas as propriedades que sabemos pertencerem-lhe claramente]. A esta substância extensa chamamos [propriamente] corpo ou substância das coisas materiais.

O estabelecimento da natureza das coisas corporais é posteriormente ratificado nos artigos seguintes, nos quais Descartes enfatiza que as mesmas não devem ser caracterizadas por suas qualidades secundárias, mas por uma propriedade essencial: a extensão. De fato, é precisamente isso que encontramos no artigo 4, no qual o autor afirma (DESCARTES, 2006 [1644], p. 60) :

Procedendo assim, saberemos que natureza da matéria ou do corpo em geral não consiste em ser uma coisa dura, pesada ou colorida, ou que afeta os sentidos de qualquer outra maneira, mas que é apenas uma substância extensa em comprimento, largura e altura.

Ora, a determinação da natureza dos corpos dotados de cor, peso, rigidez, entre outras qualidades secundárias, é resultado da abstração das mesmas, estratégia claramente exposta no artigo 11, no qual Descartes, a fim de esclarecer a natureza dos corpos, apresenta um exemplo no qual todas as qualidades secundárias de uma pedra são eliminadas até que reste apenas a sua extensão, isto é, seu comprimento, largura e altura. Como ele afirma, no artigo 4 dos Princípio de Filosofia, a existência dos corpos não depende das qualidades secundárias que observamos pelos sentidos, mas 
única e exclusivamente da extensão. É importante notar que o estabelecimento da natureza das coisas corporais como extensão permitirá justamente o tratamento matemático e mecânico dos corpos. Quanto a este último aspecto, é importante notar que a concepção de matéria presente neste momento do texto de 1644 deve ser contrastada com as formulações que aparecem em textos anteriores, como O mundo e Os meteoros. Nestes últimos, Descartes procura mostrar que a matéria é composta de pequenas partes ou corpúsculos arranjados de tal forma que há, entre eles, pequenos intervalos, os quais são preenchidos por uma matéria muito sutil. Como veremos a seguir, tal concepção estará presente na distinção entre corpos duros e corpos líquidos, assunto abordado tanto no ensaio de 1637 quanto na obra de 1644.

Até esse momento do texto, podemos perceber que apenas os corpos são definidos como extensão. Todavia, o mundo exterior não é composto apenas de corpos, mas também do meio no qual eles estão dispostos e se movimentam. Segundo Descartes, o espaço também deve ser compreendido como extensão e, nesse sentido, em nada difere dos corpos nele presentes. Como ele afirma no artigo 11 (DESCARTES, 2006 [1644], p. 64):

Depois de assim termos examinado esta pedra descobrimos que a verdadeira ideia que nos fez conceber que é um corpo consiste unicamente em apercebermos distintamente de que é uma substância extensa em comprimento, largura e altura; ora, isso mesmo está compreendido na ideia de que temos do espaço, não só daquele que está preenchido pelos corpos, mas também daquele que se chama vazio.

Assim, corpos e espaço possuem a mesma natureza, uma vez que são compostos de uma mesma substância extensa, passível 
de ser infinitamente dividida, sem a necessidade de pressupor a existência do vazio ${ }^{3}$. Entendidos nesses termos, como distinguir corpos e espaço, isto é, como dar conta do fato de que, efetivamente, vemos corpos dispostos no espaço ou movimentando-se de um ponto a outro? A resposta a essa questão nos coloca não somente diante da solução do problema, mas também de outro elemento fundamental: o movimento. A fim de compreender o que está em jogo, precisamos ter em conta a natureza dos corpos líquidos, pois é justamente aí que a distinção entre corpos e espaço é claramente estabelecida. Para tanto, é preciso chamar a atenção para os artigos 54 e 58, da segunda parte dos Princípios de Filosofia. No primeiro desses artigos, levando em consideração que as partes dos corpos líquidos "cedem facilmente o seu lugar e não oferecem resistência às nossas mãos quando os encontram", o que não ocorre com os corpos duros, Descartes conclui (DESCARTES, 2006 [1644], p. 84):

Donde se segue que um corpoélíquido quando está dividido em muitas partículas que se movem separadamente de maneiras diferentes, e é duro quando todas as suas partes se tocam entre si [sem precisarem de movimento para se afastarem reciprocamente].

Quanto ao artigo 58, basta fazer referência ao seu enunciado (DESCARTES, 2006 [1644], p. 87): “Um corpo não deve ser considerado totalmente líquido relativamente ao corpo duro que o rodeia se algumas de suas partes se moverem menos depressa do que o corpo duro".

Tendo em vista os dois artigos, podemos concluir que a diferença entre corpo e espaço, ou mais propriamente entre corpo duro e corpo líquido, é justamente que as partes do primeiro 
movem-se muito mais lentamente do que as do segundo. Ainda que ambos sejam compreendidos como uma substância extensa, o que permite diferenciá-los é justamente a velocidade com que suas partes se movem.

É a partir dessas noções, de corpo duro e de corpo líquido, que a explicação sobre os movimentos celestes é construída. $\mathrm{O}$ que certamente não deverá causar qualquer surpresa, uma vez que, utilizando aquilo que poderíamos denominar de princípio de homogeneidade, Descartes sustenta, nos artigos 22 e 23 da segunda parte dos Princípios de Filosofia, que a Terra e os céus são constituídos da mesma matéria e que só podemos conhecêla porque é extensa. Assim, trata-se de regiões homogêneas, de maneira que não é mais possível sustentar a antiga distinção aristotélica entre mundo sublunar e supralunar. Se Terra e céus são feitos de uma mesma matéria, então é natural que os movimentos observados nos céus possuam alguma proximidade com aqueles que observamos no interior da Terra. É precisamente essa concepção que permitirá o tratamento mecanicista dos movimentos celestes, supondo o transporte dos orbes celestes em um céu líquido.

\section{AS HIPÓTESES COSMOLÓGICAS DE DESCARTES}

Nosso objetivo nesse momento é fazer uma análise das questões astronômicas e filosóficas que se apresentam no terceiro livro dos Princípios da filosofia, ou seja, uma exposição acerca da teoria dos vórtices elaborada por Descartes. Essa exposição tem como finalidade apontar as diretrizes para a concepção cartesiana da teoria dos vórtices, presente nos artigos 19-31 da terceira 
parte. Foi justamente em virtude deste objetivo que dedicamos as duas primeiras partes do presente artigo à exposição de um quadro geral sobre os problemas cosmológicos que prevaleciam na época de Descartes e, ainda, uma apresentação geral sobre as principais obras deste autor relacionadas direta ou indiretamente com esses problemas cosmológicos. Assim, uma vez apresentado o contexto no qual a teoria dos vórtices está inserida, passamos propriamente a sua análise.

Descartes elaborou a teoria dos vórtices como uma alternativa tanto para o sistema de Copérnico como para o sistema híbrido de Brahe. Ao iniciar a apresentação da sua teoria dos vórtices, Descartes, no artigo 19 da terceira parte dos Princípios, coloca a sua intenção (DESCARTES, 2006 [1644], p. 98):

Sem discordar minimamente com ambos, terei mais cuidado do que Copérnico em não atribuir movimento algum à Terra e procurarei tornar as minhas razões mais verdadeiras do que as de Tycho. Por isso, proporei aqui a hipótese que me parece ser a mais simples de todas e a mais apropriada [quer para conhecer os fenômenos como para lhes buscar as causas naturais]; contudo, aviso que não pretendo que seja acolhida como totalmente conforme com a verdade, pois pode ser falsa.

Por esse artigo, lemos claramente que Descartes não segue Copérnico, pois não atribui movimento a Terra. Uma razão de cunho metafísico talvez explique essa necessidade, isto é, a metafísica cartesiana, ligada à impossibilidade de ações à distância, determina que toda ação deve ser feita por contato ou choque. Não é necessário, portanto, que a Terra se mova nessa perspectiva, é suficiente que ela seja conduzida por algo; este algo 
é o movimento em vórtices que o Sol provoca nela e nos outros corpos que pertencem ao seu sistema de movimentos. Outra explicação pode ser de cunho político e religioso, isto é, não era interessante na época de Descartes defender o movimento da Terra; lembre-se novamente o caso da desistência de Descartes de publicação de $O$ mundo, em 1633, ocasionada pela condenação de Galileu pelo Santo Ofício. Interessante também é a afirmação de que seu sistema é mais verdadeiro que o de Brahe. $\mathrm{Na}$ época de Descartes, o sistema ptolomaico já tinha sido abandonado, e o de Brahe era o preferido pelos meios acadêmicos e eclesiásticos ${ }^{4}$. Contudo, para Descartes, o sistema híbrido de Brahe não apresenta, como ele mesmo diz, um grau de certeza simples.

Feita a apresentação no artigo 19, Descartes passa a expor a sua teoria dos vórtices. Inicialmente, Descartes elabora quatro suposições para dar operacionalidade a sua teoria. Vejamos, então, quais são as hipóteses cartesianas para a elaboração da teoria dos vórtices.

Em primeiro lugar, Descartes assume que as estrelas estão muito afastadas de Saturno (artigo 20), e isto devido ao problema das distâncias. Um problema para o copernicanismo, e talvez o que mais incomodou os astrônomos que seguiram essa nova proposta, foi a questão da falta de observação de paralaxe. Como não era possível a detecção de uma paralaxe estelar, isto serviu como um grande argumento contra o copernicanismo.

Em segundo lugar, assume que o corpo do Sol (artigos 21 a 23) tem uma matéria extremamente líquida, com partes muito agitadas que conduzem consigo as outras partes do céu contíguas a ela.

Em terceiro lugar, Descartes sustenta que os céus são líquidos (artigos 24 e 25) ou constituídos de uma matéria líquida, como atesta a seguinte passagem (DESCARTES, 2006 [1644], p. 100): 
Em terceiro lugar, pensamos que a matéria do céu é líquida, assim como a que constitui o Sol e as estrelas fixas. Essa opinião é agora comumente aceite por todos os astrônomos, porque de outro modo é quase impossível explicar corretamente os fenômenos.

A questão, todavia, não foi bem colocada por Descartes. A suposição de que os céus são líquidos não era algo aceito sem mais pelos astrônomos da época. Kepler, por exemplo, tem uma postura diferente, justamente por aceitar que existam forças a distância, a questão da constituição líquida do céu não era algo admitido por ele.

Em quarto lugar, o filósofo francês afirma, no artigo 25, que os céus transportam consigo todos os corpos que contêm (DESCARTES, 2006 [1644], p. 100):

Mas parece-me que muitos se enganam quando atribuem ao céu a propriedade de ser líquido e ao mesmo tempo o imaginam como um espaço completamente vazio que resiste ao movimento dos outros corpos e que não tem nenhuma força para os mover e arrastar consigo. Além de um tal vazio não poder existir na Natureza, tem em comum com todos os líquidos o seguinte: a razão porque resistem aos movimentos dos outros corpos não está em terem menos matéria do que eles, mas em terem tanta ou mais agitação, e porque as suas partículas facilmente se determinam a mover-se de todos os lados. E quando todas se movem conjuntamente para um só lado, isso implica necessariamente que levem consigo todos os corpos que envolvem e rodeiam por todos os lados, não sendo impedidos de acompanhá-los por qualquer causa externa, ainda que estes corpos duros e sólidos estejam em completo repouso, como evidentemente se segue de quando se disse da natureza dos corpos líquidos [Parte II, Art. 61]. 
Podemos retirar algumas coisas desse artigo. Em primeiro lugar é incompatível admitir que o céu contenha matéria (que, para Descartes, é líquida) e, ao mesmo tempo, sustentar que é vazio. Essa questão não apresenta dificuldades. Contudo, admitir que os céus sejam líquidos é, para Descartes, uma hipótese; de maneira que isto não prova que não haja vazio no céu. Mas admitindo que o céu seja líquido e que não haja vazio, podemos entender como funciona a teoria dos vórtices. Em linhas gerais, os planetas que pertencem a um sistema delimitado, ou seja, que pertencem a um grande vórtice, como no caso do nosso sistema solar, são conduzidos em seus movimentos não por si próprios, mas pela ação exercida pelo corpo central. Inicialmente, temos que "a razão porque resistem aos movimentos dos outros corpos não está em terem menos matéria do que eles", isto é, não é a relação entre a quantidade de matéria que determina a submissão de um corpo ao movimento de outro, "mas em terem tanta ou mais agitação, e porque as suas partículas facilmente se determinam a mover-se de todos os lados". Ou seja, é uma questão de quantidade de agitação das partículas que está em jogo. E "quando todas se movem conjuntamente para um só lado, isso implica necessariamente que levem consigo todos os corpos que envolvem e rodeiam por todos os lados" Isto é, quando as partículas concentram-se no centro, que no caso é o corpo do Sol, elas trazem todas as partículas contíguas a elas, a saber, os planetas. Portanto, a teoria dos vórtices é estabelecida pela aceitação de que o céu contém mais agitação e as suas partículas movem-se para todos os lados e, se moverem-se todas, ou uma grande parte, para um só lado, isso permitirá a condução dos corpos que estão contidos nelas.

Em quinto lugar, Descartes sustenta, no artigo 26, que a Terra não se move por si, mas é conduzida pelo movimento contíguo do corpo do Sol (DESCARTES, 2006 [1644], p. 101): 
Em quarto lugar, vemos que a Terra não é amparada por colunas, nem está suspensa no ar por cabos, mas rodeada de um céu muito liquido por todos os lados, e por isso pensamos que está em repouso e que não tem propensão para o movimento, dado que não o observamos nela. Mas isso não impede que ela seja levada pelo curso do céu e siga o seu movimento apesar de não a vermos mover-se: é como um barco que, não sendo levado pelo vento nem pela força de remos, se mantém preso pelas âncoras, permanecendo em repouso por meio do mar; ainda que o fluxo e o refluxo daquela grande massa de água provavelmente o arraste consigo de forma insensível.

A afirmação de que a Terra, assim como os outros planetas, não está amparada por colunas ou outro tipo de sustentação é um aspecto fundamental que, por sua vez, está relacionado com a forma como Descartes entende não somente a sua localização, mas também o seu comportamento. Para ele, a Terra é sustentada no céu, e comporta-se nesse meio, de modo hidrostático. Ou seja, a Terra comporta-se como um corpo duro imerso em um meio líquido, o que nos remete às definições e ao comportamento de corpo duro e corpo líquido, expostas na segunda parte dos Princípios de filosofia. Além disso, embora os nossos sentidos indiquem que a Terra parece estar em repouso, ela move-se porque é conduzida pelos céus líquidos. Em outras palavras, a Terra move-se e não se move ao mesmo tempo. Isso pode ser explorado de algumas maneiras. Pode-se dizer que como ela não tem condições de se movimentar por si mesma, é preciso que seja conduzida pela agitação das partículas do vórtice no qual ela está localizada.

Em sexto lugar, Descartes, no artigo 27, confere o mesmo tipo de comportamento a todos os outros planetas (DESCARTES, 2006 [1644], p. 101): 
E dado que os planetas se assemelham à Terra, porque são opacos e refletem a luz do Sol, temos motivos para crer que também se assemelham a ela, permanecendo também em repouso na parte do céu onde cada um se encontra. As semelhanças que se observa relativamente à sua localização derivam apenas do facto de seguirem o movimento da matéria que os contém.

Em sétimo lugar, encontramos a exposição de um princípio de relatividade mecânica do movimento, relacionado com o deslocamento dos planetas e, como se conclui do que foi exposto até agora, da suposição de que os planetas estão imersos em um céu líquido que, pelo movimento de suas partículas, carrega consigo os orbes celestes. Este princípio é apresentado no artigo 28 (DESCARTES, 2006 [1644], p. 101-2):

Convém aqui recordar o que anteriormente se disse sobre a natureza do movimento, isto é, propriamente falando, um corpo só é transportado da proximidade daqueles que lhe são imediatamente contíguos - e que consideramos em repouso - para a proximidade de outros. Mas, na prática, muitas vezes chamamos movimento a toda ação que faz com que um corpo passe de um lugar para outro, e neste sentido pode dizer-se que uma coisa está e não está ao mesmo tempo em movimento conforme o lugar que lhe determinamos. Donde se segue que na Terra e nos outros planetas não há nenhum movimento com a significação própria deste termo, uma vez que não são transportados da proximidade da parte do céu que lhe são contíguas (e que consideramos em repouso). Com efeito, para serem transportados seria necessário que se afastassem simultaneamente de todas as partes do céu tomadas em conjunto, o que não acontece: mas como a matéria do céu 
é líquida e as partes que a compõem são muito agitadas, sempre que algumas destas partes se afastam do planeta contíguo, também as outras se afastam; e isto por um movimento que lhes é próprio e que devemos atribuir a elas e não ao planeta que deixam. É o que acontece com as deslocações parciais do ar ou da água que ocorrem à superfície da Terra, que geralmente não atribuímos à própria Terra, mas à própria água e ao próprio $a^{5}$.

O movimento é relativo, pois depende daquilo que consideramos em repouso e daquilo que consideramos em movimento. Além disso, o movimento depende do lugar no qual determinado corpo esteja localizado. Assim, a Terra não se move por si, mas é conduzida pelos céus que a contém, o que faz que Descartes não se comprometa com a admissão do movimento da Terra em seu sentido mais forte, ou seja, o sentido no qual Copérnico e os copernicanos afirmavam tal movimento.

\section{CONSIDERAÇÕES FINAIS}

Westfall caracteriza a importância da teoria dos vórtices de Descartes da seguinte maneira (WESTFALL, 1980, p. 58-9):

A teoria dos vórtices constituiu o primeiro sistema aparentemente plausível estabelecido para substituir as esferas cristalinas. $\mathrm{Na}$ realidade, a mecânica celeste de Kepler havia precedido, mas o sistema de Kepler foi construído a partir de princípios inaceitáveis para a filosofia mecanicista. Os vórtices de Descartes, inútil dizer, eram aceitáveis e dominaram durante meio século as descrições do céu. Para entender o pensamento científico 
do século XVII, é importante saber o que se pretendia ou não se pretendia explicar. Os vórtices ofereciam uma explicação mecânica aos grandes fenômenos celestes. Indicavam porque os planetas giram ao redor do Sol, todos na mesma direção e todos (praticamente) no mesmo plano. Mediante a introdução encoberta de fatores arbitrários, explicavam o fato dos planetas moverem-se mais lentamente quanto mais afastados estão do Sol. Tais coisas, contudo, eram apresentadas como consequência da matéria em movimento, sem recorrer a quaisquer poderes ocultos. Para a ciência do século XVII, foi importante o tipo de explicação mecanicista que ofereciam os vórtices, e não é difícil de entender-se a atração dessa teoria. O que a teoria dos vórtices não tentou abordar foram os detalhes precisos das órbitas planetárias que constituíam o domínio da astronomia técnica. Descartes não mencionou as três leis de Kepler, e é difícil pensar como ele poderia tê-las deduzido dos vórtices. Mas o tipo de descrição matemática que representam as leis de Kepler também foi importante para a ciência do século XVII. A filosofia mecanicista, com a sua concentração nas causas físicas, existiu em oposição à tradição pitagórica de descrição matemática. $\mathrm{O}$ maior sucesso da ciência do século XVII, a obra de Isaac Newton, constituiu na resolução de tal problema.

O interessante dessa passagem de Westfall é que ele caracteriza a teoria dos vórtices de Descartes como o primeiro sistema plausível para substituir a teoria das esferas cristalinas, fundamental para um aristotélico. Mas em relação à questão posta por Brahe, isto é, o que faz um planeta se movimentar? Descartes teria também resolvido este problema? Acreditamos que a questão deve ser posta da seguinte maneira: se Descartes assume que o universo celeste é um pleno e que os turbilhões 
ocorrem porque são constituídos de líquidos, então esses líquidos são constituídos de matéria e terão alguma ação na trajetória de outros corpos celestes além dos planetas, tais como cometas. Desse modo, teríamos que concluir que um turbilhão deve afetar a trajetória dos cometas tal como deve fazê-lo no caso dos planetas. Contudo, observa-se que as suas trajetórias são constantes e não são afetadas por tais turbilhões. Por outro lado, se o líquido que contém os sistemas planetários não é de natureza tal como, por exemplo, a da água, isto é, se não é matéria, então é uma entidade com o mesmo estatuto de força. Descartes ficou com a primeira opção. Contudo, isso o levou a elaborar uma explicação muito complexa para dar conta do movimento de um cometa, como podemos notar nos artigos 119 a 139.

Acreditamos que a dificuldade é que a teoria dos vórtices de Descartes, apesar de sofisticada para a época (por tentar explicar mecanicamente a problema dos movimentos planetários através de recursos mecânicos) está no mesmo plano das explicações mecânicas de Aristóteles, com a diferença de que em vez de esferas encaixadas em esferas (as esferas concêntricas de Eudoxo), Descartes utiliza vórtices ou turbilhões. Mas o problema posto por Brahe já não era esse, isto é, o de construir um modelo mecânico com entidades extensas, seja com esferas, com relógios ou com líquidos, mas o de fornecer uma explicação que tanto resolvesse as regularidades observadas nos movimentos dos planetas, bem como determinasse um modelo cosmológico que explicasse por que outros fenômenos celestes, tal como a trajetória de um cometa, percorrem livremente o céu sem sofrerem qualquer impedimento. 


\section{NOTAS}

${ }^{1}$ Professor de Filosofia da Ciência da Universidade Federal de São Paulo, toclare@uol.com.br.

${ }^{2}$ Professor de Filosofia da Ciência da Universidade Federal do ABC, paulo. tadeu@ufabc.edu.br.

${ }^{3} \mathrm{~A}$ recusa do vazio é seguramente um dos temas centrais da filosofia natural de Descartes e, notadamente, da sua teoria sobre a natureza da matéria. Vale lembrar neste momento que os pequenos intervalos existentes entre as partes ou corpúsculos que compõem a matéria não são, para ele, vazios, mas preenchidos por uma matéria muito sutil. Dados os limites do presente artigo, não abordaremos mais detalhadamente esse tema.

${ }^{4}$ De acordo com Leitão, a partir de 1620, o sistema de Brahe passa a ser oficialmente adotado pela Companhia de Jesus (cf. LEITÃO, 2008, p. 31).

${ }^{5} \mathrm{~A}$ referência aos deslocamentos parciais da água e do ar está relacionada com os fenômenos discutidos por Descartes em Os meteoros. O movimento das partículas que formam o ar e a água é discutido pelo autor no segundo, terceiro, quarto, quinto e sexto discursos do ensaio de 1637.

\section{REFERÊNCIAS}

ADAM, C. \& TANNERY, P. (Ed.). Ceuvres de Descartes. Paris : Vrin/Centre National du Livre, 1996. 11 v. (AT)

BEYSSADE, J. M. \& KAMBOUCHNER, D. (Ed.). René Descartes. CEuvres complètes. Paris: Gallimard, 2009 [1637]. v. 3: Discours de la méthode et essais.

COPÉRNICO, N. As revoluções dos orbes celestes. Tradução A. Dias Gomes e Gabriel Domingues Introdução e notas Luis Albuquerque. Lisboa: Fundação Calouste Gulbenkian, 1996 [1543]. 
DE BUZON, F. La première publication de Descartes. In: BEYSSADE, J. M. \& KAMBOUCHNER, D. (Ed.). René Descartes. Euvres complètes. Paris: Gallimard, 2009 [1637].v. 3: Discours de la méthode et essais, p. 15-41.

DESCARTES, R. Princípios de filosofia. Tradução de João Gama. Lisboa: Edições 70, 2006 [1644].

DESCARTES, R. O mundo ou tratado da luz/O homem. Tradução de César Augusto Battisti e Marisa Carneiro de Oliveira Franco Donatelli. Campinas: Editora UNICAMP, 2009 [1633].

FAVARO, A. (Ed.) Edizione nazionale delle opere di Galileo Galilei. Firenze: Barbera, 1933 [1891]. 20 v. (EN)

GALILEI, G. Ciência e fé: cartas de Galileu sobre o acordo do sistema copernicano com a Bíblia. Organização e tradução Carlos Arthur R. do Nascimento. São Paulo: Editora UNESP, 2009.

GAUKROGER, S. Descartes: uma biografia intelectual. Tradução de Vera Ribeiro. São Paulo: Contraponto, 1999.

LEITÃO, H. O Debate cosmológico na "Aula da Esfera" do Colégio de Santo Antão. In: LEITÃO, H. (org.) Sphaera Mundi: a ciência na Aula da Esfera. Lisboa: Biblioteca Nacional de Portugal, 2008, p. 27-44.

LEITÃO, H. Estudo introdutório. In: GALILEI, G. Sidereus nuncius: o mensageiro das estrelas. 3. Ed. Tradução, estudo e notas Henrique Leitão. Lisboa: Fundação Calouste Gulbenkian, 2010 [1610]. p. 19-136.

MARICONDA, P. R. \& VASCONCELOS, J. Galileu e a nova física. São Paulo: Odysseus, 2006. 
TOSSATO,C.R.Discussão cosmológica erenovação metodológica na carta de 9 de dezembro de 1599 de Brahe a Kepler. In: Scientiae Studia. São Paulo, v. 2, n. 4, out.-dez. 2004, p. 537-65.

WESTFALL, R. La construcción de la ciencia moderna. Tradução de Ramón Jansana Ferrer. Barcelona: Editorial Labor S. A., 1980. 